\title{
Prosthetic rehabilitation of maxillary lateral incisors agenesis using dental mini-implants: a multicenter 10-year follow-up
}

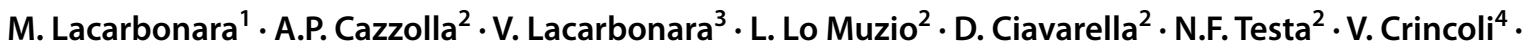 \\ D. Di Venere ${ }^{3}$ A. De Franco ${ }^{3}$ - D. Tripodi ${ }^{5}$. F.R. Grassi ${ }^{4} \cdot$ M. Capogreco ${ }^{1}$
}

Received: 25 January 2020 / Accepted: 1 September 2021 / Published online: 26 September 2021

(c) The Author(s) 2021

\begin{abstract}
Objectives Implants are used to replace congenitally missing lateral incisors but often the space across the alveolar crest is too narrow to permit their use. This multicenter study (Dental Clinic of the University of Foggia, Odontostomatology Clinic of the University of L'Aquila) evaluated the efficacy of mini-implants in cases of maxillary lateral incisor agenesis with severe osseous atrophy in 10-year follow-up.

Materials and methods Forty-seven mini-implants have been inserted in 35 patients affected by lateral incisors agenesis (23 single and 12 bilateral ageneses). All patients underwent orthodontic opening of the space of the upper lateral incisors. After the insertion of the implants, the immediate, non-functional loading, positioning of crowns, presence of pain during percussion and mini-implant function, horizontal and vertical movement when a force of $5 \mathrm{~N}$ was applied, ridge loss, and plaque index have been evaluated 1 month after loading, 1 year after loading, and then every 5 years in the following 10 years. Little's test was used to evaluate the assumption that data of loss to follow-up implants are missing completely at random (MCAR) and that a complete-case scenario could be adopted. Wilcoxon test was carried out to look statistically significant differences between the various parameters resulting in the complete-case scenario and those assumed for the worst scenario. The software R (v. 3.6.1, 2019) was employed to perform the statistical analysis.

Results The results obtained over 10 years range from $89 \%$ of success rate in a worst-case scenario to the $100 \%$ using a complete-case analysis with satisfactory values of marginal bone resorption and good conditions of the peri-implant tissue. Ten-year follow-up using complete-case analysis shows survival rates of $100 \%$ for implants with no signs of peri-implantitis, stability of the marginal bone levels and soft tissue around the dental implants.

Conclusions The data collected show very good implant stability, absence of progressive peri-implantitis, and satisfactory aesthetical results in time (no signs of infraocclusion).

Clinical relevance Mini-implants can be considered a valid and stable over time solution in the restorative treatment of maxillary lateral incisors agenesis.
\end{abstract}

Keywords Dental implants · Prosthodontic materials and techniques · Esthetics related to prosthodontics · Implant dentistry

Lacarbonara M. and Cazzolla A.P. equally contributed as first author for this manuscript.

D. Ciavarella

angela_cazzolla.568044@unifg.it

1 Department of Life, Health and Environmental Sciences, Dental Clinic, University of L'Aquila, L'Aquila, Italy

2 Department of Clinical and Experimental Medicine, University of Foggia, Foggia, Italy

\section{Introduction}

The prevalence of permanent dentition agenesis is reported to range from 2.2 to $7.6 \%$ with a variable prevalence in different ethnic groups and a modest preference toward females

3 Interdisciplinary Department of Medicine, University of Bari, Bari, Italy

4 Department of Basic Medical Sciences, Neurosciences and Sensory Organs, University of Bari, Bari, Italy

5 Department of Medical, Oral and Biotechnological Sciences, University of Chieti-Pescara, Chieti, Italy 
[1]. The most commonly reported teeth missing are mandibular second premolars (44\%), maxillary lateral incisors (22.9\%), maxillary second premolars $(21.2 \%)$, mandibular central incisors $(3.5 \%)$ and mandibular lateral incisors $(2.5 \%)$. Bilateral ageneses of a particular tooth have been highlighted with maxillary lateral incisors being most common (54\%) followed by maxillary second premolars (49\%), mandibular second premolars (46\%) and mandibular central incisors (41\%) [2].

According to Bozga et al., the range of agenesis of maxillary lateral incisors is $2.2 \%$ to $10.1 \%$ [3], whereas Alvesalo and Portin [4] reported a prevalence of maxillary lateral incisor agenesis of $0.52-8.4 \%$, although studies on the Northwestern European population showed a lower congenital prevalence, from 1 to $2 \%$ [5].

Dental agenesis is often associated with tooth ectopias and/or other abnormal dental conditions $[6,7]$ like a smaller or a conoid tooth on the opposite side of the arch. In such cases, the canines are often mesially or lingually positioned, compared with their normal position, the midline being deviated towards the side affected by the agenesis.

Sometimes, agenesis of maxillary lateral incisors is associated with rare diseases or severe syndromes with problems of oral rehabilitation [8-15].

The protocol used for treating agenesis of maxillary lateral incisors depends more on practice organization and the clinical skills available than on considerations regarding treatment effectiveness.

There are at least four options for treating congenital agenesis of the maxillary lateral incisors. These include (1) conservative approach, an aesthetic remodeling of the deciduous maxillary lateral incisor employing a composite resin [16], (2) orthodontic treatment to close the gap with replacement using a reshaped canine [16], (3) orthodontic treatment to open a space with placement of cantilevered resin-bonded fixed dental prostheses [17-19] and (4) orthodontic treatment to open the space with placement of implant-supported fixed prosthetic restorations [17, 20, 21]. The decision for the most adequate treatment setting must consider the type of malocclusion, the anterior teeth relationship, space availability, and the condition of the adjacent tooth [22].

In presence of severe bone atrophy, dental mini-implants may provide a valid solution in patients with narrow alveolar ridges when there is a small interdental space (such as in cases with lateral agenesis).

Mini-implants consist of fixtures whose diameter is between 13/16 and 53/64 inches made up of 5th grade, extrastrong, titanium, sandblasted and acid-etched, with an insertion torque greater than $95 \mathrm{Ncm}$. At the beginning, they have been used as main fixtures in full-arch implant or prosthetic rehabilitation. In 1999, the Food and Drug Administration (FDA) approved mini dental implants as a safe and permanent option for tooth replacement and they have been used for single-tooth restoration and in cases of a transversal bone deficit.

The hypothesis of this study is to evaluate the efficacy of mini-implants in cases of maxillary lateral incisor agenesis with patients affected by severe osseous atrophy (Type B: breadth 7/64-13/64 in, 25/64-31/64 height, length 7/64-13/64), bone density according to Misch D-3, 350-850 $\mathrm{uH} \mathrm{B}[23]$ in the long term (10-year follow-up).

\section{Materials and methods}

This multicenter study was conducted from January 2009 to June 2019, in accordance with the provisions of the Declaration of Helsinki at the Dental Clinic of the University of Foggia and the Odontostomatology Clinic of the University of L'Aquila. The study has been approved by the ethics committee of Foggia and L'Aquila (Italy) (protocol number 153CE-2020/30-11-2020) and informed consent was obtained. Of 46 patients (28 females (61\%) age $18.5 \pm 1.5$ and 18 males (39\%) age $19.5 \pm 2.2$ ) with lateral incisors agenesis, 16 patients were excluded because 2 finished chemotherapy and 1 radiotherapy recently, 2 presented uncontrolled diabetes mellitus, 1 used corticosteroids and 5 smoke more than 10 cigarettes per day. Five did not carry out periodic controls ( 2 after the first month, 1 after 1 year and 2 after 5 years) and 30 patients fulfilled the inclusion criteria. Thirty patients (11 men (37\%) and 18 (63\%) women) affected by maxillary lateral incisor agenesis and submitted to implant replacement were recruited in the study group using complete-case analysis.

In 18 patients (11 females and 7 males), the anomaly was unilateral (60\%), while in 12 patients ( 8 females and 4 males), it was bilateral (40\%) (Figs. 1, 2).

In this study, 42 mini-implants with a diameter of $2.7 \mathrm{~mm}$ and $3 \mathrm{~mm}$ (Milo Model, Intra-lock) were examined.

Thirty-five patients fulfilled the inclusion criteria: 14 men $(40 \%)$ and $21(60 \%)$ women affected by maxillary lateral incisor agenesis and submitted to implant replacement were recruited in the study group.

In 23 patients (13 females and 10 males), the anomaly was unilateral $(66 \%)$, while in 12 patients ( 8 females and 4 males), it was bilateral (40\%) (Figs. 1, 2).

In this study, 47 mini-implants with a diameter of $2.7 \mathrm{~mm}$ and $3 \mathrm{~mm}$ (Milo Model, Intra-lock) were examined.

The facial type, the esthetic profile and smile were evaluated clinically [24]. Cephalometric values, molar class, the degree of dentobasal crowding and disharmony, the OVJ and OVB values were evaluated. Further parameters examined were the presence or absence of third molars, position, size and shape of the canines.

The patients included in this study had to respect the following parameters: 
Fig. 1 a Maxillary lateral incisors agenesis: orthodontic opening of the space in regions 1.2 and 2.2. b Radiographic evaluation of alveolar crest in region 1.2. c Radiographic evaluation of alveolar crest in region 2.2. d Post-surgical implant sites in regions 1.2 and 2.2. e Radiographic evaluation post-surgical implant site in region 1.2. $\mathbf{f}$ Radiographic evaluation postsurgical implant site in region 2.2. g Peri-implant tissue aspect after 1 month. h Peri-implant tissue aspect after 1 year. $\mathbf{i}$ Peri-implant tissue aspect after 5 years. 1 Peri-implant tissue aspect after 10 years.
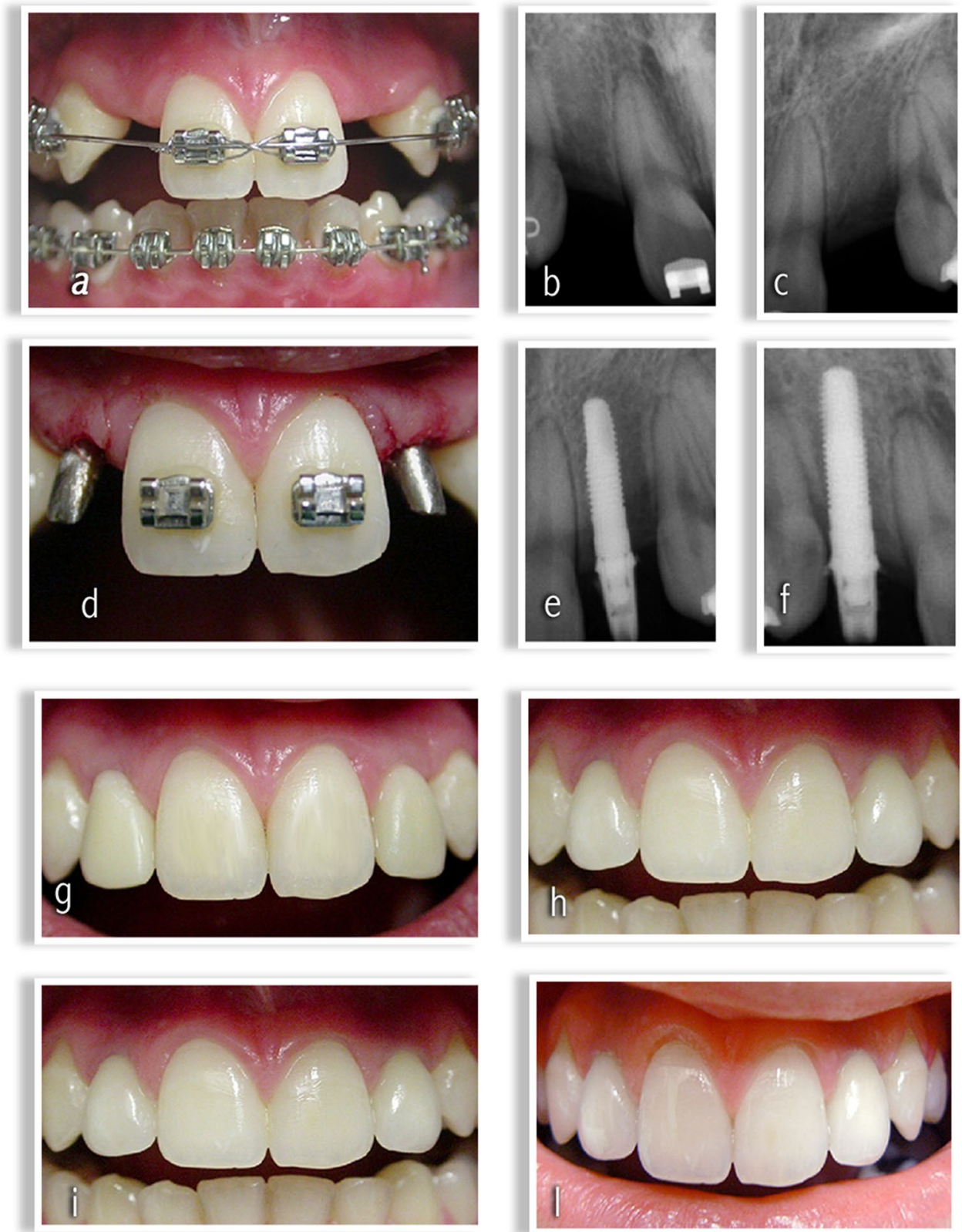

- Subscription of informed consent.

- Presence of adjacent dental roots to evaluate the implant site.

- Probable primary implant stability.

- Bone density of type D2 B or D3 according to Mish.

- An average bone thickness from the buccal to the lingual aspect of $4 \pm 1 \mathrm{~mm}$.

- The edentulous space, estimated from the distal aspect of the central incisor to the mesial aspect of the canine, measured $5 \pm 1 \mathrm{~mm}$.

- Bone height measured about $13 \pm 2 \mathrm{~mm}$, estimated from the margin of the alveolar ridge to the floor of the nose.

Patients with the following criteria were excluded from the study:
- Known or suspected presence of malignant oral cavity pathology.

- Previous clinical history of radiotherapy of the head-neck region.

- History of chemotherapy within 5 years prior to surgery.

- Systemic or local diseases that could have compromised post-operative healing and / or implant osseointegration processes.

- Uncontrolled diabetes mellitus.

- Systematic use of drugs such as corticosteroids or other drugs (antiresorptive or antiangiogenic therapy for the management of osteoporosis and other cancer-related conditions [25-27].

- Smoking 10 or more cigarettes per day. 

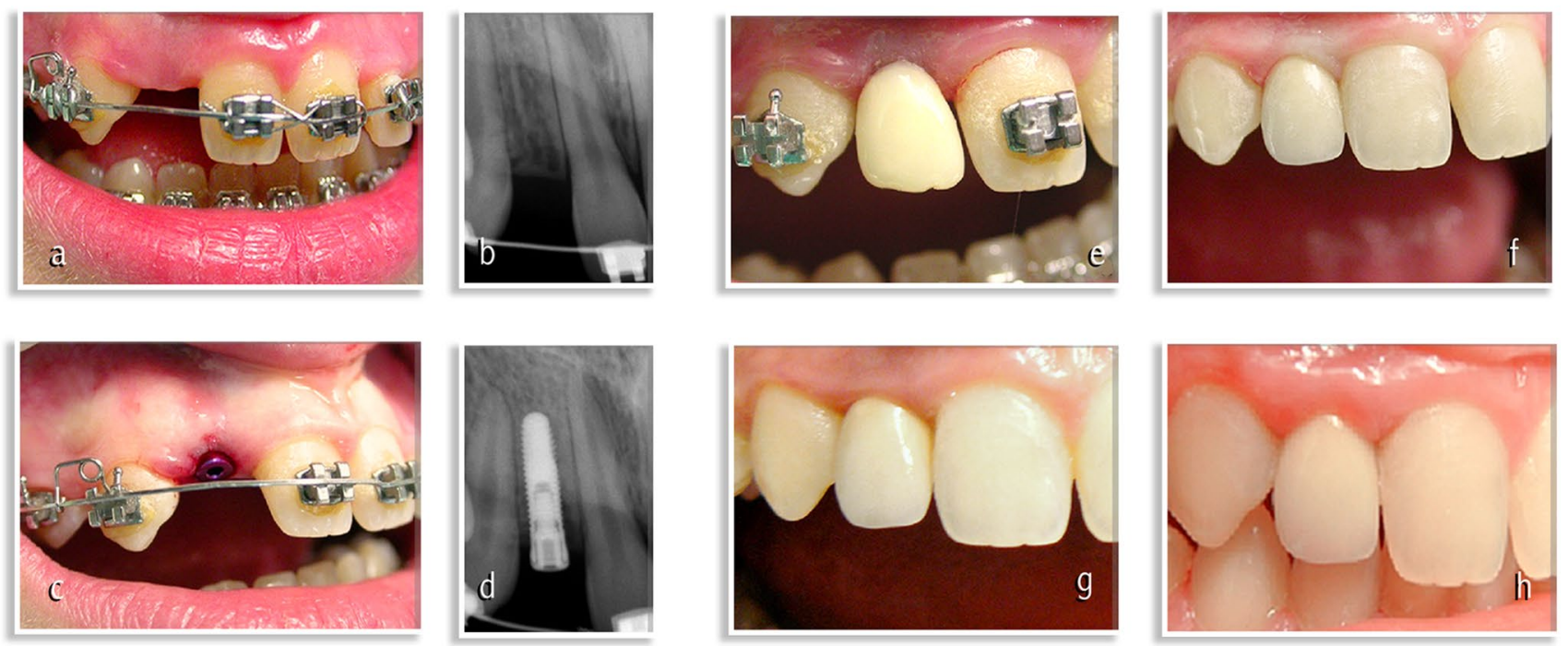

Fig. 2 a Maxillary lateral incisor agenesis: orthodontic opening of the space in regions 1.2. b Radiographic evaluation of alveolar crest in region 1.2. c Post-surgical implant sites in regions 1.2 and 2.2. d Radiographic evaluation post-surgical implant site in region 1.2. e
Peri-implant tissue aspect after 1 month. f Peri-implant tissue aspect after 1 year. $\mathbf{g}$ Peri-implant tissue aspect after 5 years. $\mathbf{h}$ Peri-implant tissue aspect after 10 years.

- Vertical and horizontal mobility in the presence of a force of $5 \mathrm{~N}$ (Fix.) [31];

- Amount of alveolar bone resorption through four-point peri-implant probing (i.e. mesial, buccal, distal and palatal-BR) [32];

- Bleeding index according to Loe and Silness (BI) [33, 34];

- Assessment of vertical changes of mini-implants to the adjacent teeth by clinical evaluation (infraocclusion) and intraoral radiographs using method reported in literature [35].

These parameters (Table 1) were followed for a period of 10 years.

Follow-up controls were performed 1 month after loading, 1 year after loading and then every 5 years in the following 10 years.

In order to evaluate the efficacy in the long term of mini-implants Wilcoxon test was carried out. In particular, Wilcoxon test was used to evaluate whether there were statistically significant differences between the different parameters taken into consideration in the follow-up. $p$-value threshold of 5\% was adopted for the test used. The software R (v. 3.6.1, 2019) was employed to perform the statistical analysis.

Loss to follow-up's data have been analyzed using Little's test [36] to evaluate the assumption that data of loss to follow-up implants are missing completely at random (MCAR) [37] and that a complete-case scenario could be adopted. 
Table 1 The parameters evaluated

\begin{tabular}{|c|c|c|}
\hline Parameters & Value & Description \\
\hline \multirow[t]{2}{*}{ A-Pain (ref.28) } & 0 & Absence \\
\hline & 1 & Presence at the palpitation, percussion or during the function (failure) \\
\hline \multirow[t]{3}{*}{ B-Rigid fixation (ref. 29) } & 0 & $\begin{array}{l}\text { Absence of visible movements both horizontally and vertically in the pres- } \\
\text { ence of a force of } 5 \mathrm{~N} \text { (about } 500 \mathrm{~g} \text { ) }\end{array}$ \\
\hline & 1 & From 0 to $0.5 \mathrm{~mm}$ of horizontal mobility d.p.c., absence of vertical mobility \\
\hline & 2 & $\begin{array}{l}\text { More than } 0.5 \mathrm{~mm} \text { of horizontal mobility d.p.c., presence of vertical mobility } \\
\text { (failure) }\end{array}$ \\
\hline \multirow[t]{4}{*}{ C-Amount of alveolar bone resorption (ref.30) } & 0 & Less than $2 \mathrm{~mm}$ of bone crest loss \\
\hline & 1 & Loss of bone crest between 2 and $3 \mathrm{~mm}$ \\
\hline & 2 & Loss of bone crest between 3 and $5 \mathrm{~mm}$ \\
\hline & 3 & Progressive and uncontrollable bone loss (failure) \\
\hline \multirow[t]{3}{*}{ D-Bleeding index (Loe and Silness) (ref. 31-32) } & 0 & Absence of bleeding \\
\hline & 1 & Bleeding not associated with bone loss (with remission after oral hygiene) \\
\hline & 2 & Bleeding associated with bone crest loss (failure) \\
\hline
\end{tabular}

Patients lost to follow-up been also been the subject of a telephone survey to investigate the reasons for their missing to the follow-up appointments.

In order to evaluate the efficacy in the long term of miniimplants Wilcoxon test was carried out to evaluate statistically significant differences over time (at 1 month, at 1 year, at 5 years and at 10 years) between the parameters mentioned above both in case of a complete-case analysis (in which five implants loss to follow-up have been ignored) that in the worst case scenario (in which implants loss to follow-up are assumed to have all failed).

Finally, Wilcoxon-Mann-Whitney test was carried out to look directly out for any statistically significant differences between the various parameters resulting in the completecase scenario and those assumed for the worst scenario [38].

$p$-value threshold of $5 \%$ was adopted for the tests used. Software R (v. 4.1.0, 2021) was employed to perform the statistical analysis.

\section{Surgical procedure}

On the day of surgery, each patient took antibiotic prophylaxis, with a short-term posology or a single administration of $2 \mathrm{~g}$ of Amoxicillin or $600 \mathrm{mg}$ of Clindamycin an hour before the operation. After performing regional loco anesthesia with mepivacaine and adrenaline in a concentration of 1:100,000, a total thickness flap was performed. After the exposure of the bone crest, the implant was inserted using, sequentially, a $1.5 \mathrm{~mm}$ diameter pilot drill and then two $2 \mathrm{~mm}$ and $2.5 \mathrm{~mm}$ diameter drills with sterile external irrigation flow. The implant was taken sterile and placed in the prepared implant site. By means of a surgical contra-angle, the implant was inserted at a speed between 15 and $20 \mathrm{rpm}$ and with a torque not exceeding $35 \mathrm{Ncm}$. The torque required for final positioning was applied manually by means of a torque wrench (Torque-Lock), thus obtaining a primary stability of $50 \mathrm{Ncm}$. The abutments were inserted into the surgical site (Figs. 1d and 2c). A single-stitch flap was sutured with a 0000 silk thread. Patients were instructed for home care and rinsed with chlorhexidine-based mouthwash at a $0.20 \%$ concentration within 10 days of surgery, twice a day.

\section{Prosthetic procedure}

Immediate non-functional loading was performed on all implants and endoral postoperative control radiography was performed (Figs. 1e-g and 2d, e). The stitches were removed after 10 days from surgery. The final impressions, made of polyether material (Permadyne Penta H, Permadyne Penta L, 3 M ESPE, Seefeld, Germany), were taken 5-7 weeks after operation. The final restorations were realized using Aureo Galvan Crowns (AGC) (Gold bath AGC electroforming, Wieland, Pforzheim, Germany) veneered with feldspathic ceramics (Noritake Super Porcelain EX-3, Noritake Co. Inc., Nagoya, Japan). They were placed 8 to 10 weeks after surgery. Patients were followed for a period of 10 years. Follow-up controls were performed 1 month after loading (Figs. $1 \mathrm{~g}$ and 2f), 1 year after loading (Figs. 1h and 2f) and then every 5 years (Figs. $1 \mathrm{i}$ and $2 \mathrm{~g}$ ) in the following 10 years (Figs. 11 and 2h).

\section{Results}

A total of 30 patients treated with 42 mini-implants were included in this analysis. 
A total of 35 patients treated with 47 mini-implants were included in this analysis. The implant has to be surgically inserted into the bone after both the orthodontic therapy and the end of the cranium-facial growth. The patients were treated with one or two implants in positions 1.2, 2.2 and implants were in two different lengths: $13 \mathrm{~mm}(n=34), 11.5$ $(n=8), 13 \mathrm{~mm}(n=38), 11.5(n=9)$. Classifications of bone quality were assessed during surgery according to Mish. According to the data of literature, there was a preference toward females $(60 \%)$. Females $(60 \%)$ are mostly affected by agenesis, in line with existing medical literature. Osseointegration was achieved for all 42 implants. Osseointegration was achieved for the implants $(n=44)$ which were revised at 1 year. All implants were reported as stable at all follow-up visits after placement of the crown and no implant failure was reported during a 10 year follow-up.

Losses to follow-up, cumulatively calculated per implant, have been $4.2 \%(n=2)$ after the first month, $6.4 \%(n=3)$ after 1 year and $10.6 \%(n=5)$ after 5 years.

Little's test was applied to missing values for each followup appointment showing always a $p$-value greater than 0.05 suggesting that the null hypothesis that the missing data was Missing Completely At Random couldn't be rejected (Table 2).

A telephone survey to investigate the reasons for patients' missing to the follow-up appointments confirmed the latter hypothesis showing the defection was to be attributable to their relocation (for study in four cases and marriage reasons in the remaining case).

All implants reviewed during follow-up visits (45 at 1 month, 44 at 1 year and 42 at 5 and 10 years) were reported as stable after placement of the crown.

Considering only the 42 implants carried by the patients who completed the 10-year follow-up, no implant failure was reported. No difference was found between male and female patients. No differences related to age were noticed. In the follow-up, no patient experienced any pain; all patients had no visible vertical and horizontal movements; no alveolar bone resorption between 2 and $3 \mathrm{~mm}$ occurred. Bleeding was presented in 7 cases (16.6\%) after 1 month, in 6 cases (20\%) after 1 year, in 5 cases (11.9\%) after 5 years and 5 cases $(11.9 \%)$ after 10 years.

Bleeding was presented in 7 implants after 1 month, in 6 implants after 1 year, in 5 implants after 5 and 10 years.

Table 2 Little's test showed that the missing data to follow-up implants are missing completely at random (MCAR)

\begin{tabular}{ll}
\hline Little test's results & \\
\hline Follow-up time & $p$-value \\
\hline 1 month & 0.283 \\
1 year & 0.272 \\
5 years & 0.0829 \\
10 years & 0.0829 \\
\hline
\end{tabular}

It was not associated with bone loss and it had a remission after oral hygiene.

Clinical and radiographic evaluations did not show vertical changes of mini implants to the adjacent anterior maxillary teeth in 10-year follow-up because in all the checks carried out, no infraocclusion of the mini-implants was detected. Furthermore, there was no radiological change performed in the distance between the point of reference located on the cervical thread of the implant and the point of reference located on the tooth adjacent to the implant (intersection point between the incisal border and the mesial side of the tooth) projected on the longitudinal axis of the implant in the 10-year follow-up.

Pain and vertical or horizontal mobility in the presence of a force of $5 \mathrm{~N}$ did not change over the considered period of 10 years, always reporting a score equal to 0 .

Wilcoxon test has been used considering the parameters that changed over time (amount of alveolar bone resorption and bleeding) while no statistical comparison could be performed on pain and vertical or horizontal mobility because their score was null.

Wilcoxon test showed a $p$-value $>0.05$ to indicate that there were no statistically significant differences between the parameters taken into consideration(amount of alveolar bone resorption and bleeding) (pain, vertical and horizontal mobility in the presence of a force of $5 \mathrm{~N}$, amount of alveolar bone resorption, bleeding) during the 10-year follow-up nor conducting a case-complete analysis on the remaining 42 implants installed in patients who were regularly followedup nor considering the worst-case scenario (in which five implants loss to follow-up are assumed to have all failed) (Tables 3 and 4).

Table 3 Wilcoxon test, used to compare data adopting the complete-case analysis. Amount of alveolar Bone Resorption (BR) and Bleeding Index (BI) score in 10-year follow-up, showed no statistically significant differences between the parameters taken into consideration ( $p$-value $>0.05$ ); $p$-value $=1$ when data in two groups are identical

\begin{tabular}{|c|c|}
\hline \multicolumn{2}{|c|}{$\begin{array}{l}\text { Wilcoxon test (complete-case } \\
\text { analysis) }\end{array}$} \\
\hline Follow-up time & $p$-value \\
\hline \multicolumn{2}{|l|}{ Bone resorption (BR) } \\
\hline 1 month vs 1 year & 0.32 \\
\hline 1 month vs 5 years & 0.32 \\
\hline 1 month vs 10 years & 0.32 \\
\hline 1 year vs 5 years & 1.00 \\
\hline 1 year vs 10 years & 1.00 \\
\hline 5 years vs 10 years & 1.00 \\
\hline \multicolumn{2}{|l|}{ Bleeding Index (BI) } \\
\hline 1 month vs 1 year & 0.65 \\
\hline 1 month vs 5 years & 0.41 \\
\hline 1 month vs 10 years & 0.41 \\
\hline 1 year vs 5 years & 0.71 \\
\hline 1 year vs 10 years & 0.71 \\
\hline 5 years vs 10 years & 1.00 \\
\hline
\end{tabular}


Table 4 Wilcoxon test, used to compare data in the worst case scenario Amount of alveolar Bone Resorption (BR) and Bleeding Index (BI) score in 10-year follow-up, showed no statistically significant differences between the parameters taken into consideration ( $p$-value $>0.05$ ); $p$-value $=1$ when data in two groups are identical

\begin{tabular}{ll}
\hline $\begin{array}{l}\text { Wilcoxon test (worst case } \\
\text { scenario) }\end{array}$ \\
\hline Follow-up time & $p$ value \\
\hline Bone resorption (BR) & \\
1 month vs 1 year & 0.18 \\
1 month vs 5 years & 0.06 \\
1 month vs 10 years & 0.06 \\
1 year vs 5 years & 0.19 \\
1 year vs 10 years & 0.19 \\
5 years vs 10 years & 1 \\
Bleeding Index (BI) & \\
1 month vs 1 year & 0.74 \\
1 month vs 5 years & 0.30 \\
1 month vs 10 years & 0.30 \\
1 year vs 5 years & 0.42 \\
1 year vs 10 years & 0.42 \\
5 years vs 10 years & 1 \\
\hline
\end{tabular}

Table 5 Wilcoxon-MannWhitney test, used to compare the results of the worst case scenario with the ones of the complete-case analysis in a 10-year follow-up, showed no statistically significant differences $(p$-value $>0.05)$

Wilcoxon-Mann-Whitney test (worst scenario vs complete case)

\begin{tabular}{ll}
\hline Follow-up time & $p$-value \\
\hline Bone resorption (BR) & \\
1 month vs 1 month & 0.18 \\
1 month vs 1 year & 0.61 \\
1 month vs 5 years & 0.61 \\
1 month vs 10 years & 0.61 \\
1 year vs 1 year & 0.20 \\
1 year vs 5 years & 0.20 \\
1 year vs 10 years & 0.20 \\
5 years vs 5 years & 0.06 \\
5 years vs 10 years & 0.06 \\
Bleeding Index (BI) & \\
1 month vs 1 month & 0.70 \\
1 month vs 1 year & 0.49 \\
1 month vs 5 years & 0.32 \\
1 month vs 10 years & 0.32 \\
1 year vs 1 year & 0.47 \\
1 year vs 5 years & 0.30 \\
1 year vs 10 years & 0.30 \\
5 years vs 5 years & 0.18 \\
5 years vs 10 years & 0.18 \\
\hline
\end{tabular}

Moreover, Wilcoxon-Mann-Whitney test showed a $p$-value $>0.05$, thus indicating that there were no statistically significant differences, comparing the results for the parameters taken into consideration from the completecase analysis with the data of the worst case scenario (Table 5).

\section{Discussion}

The therapeutic plan for congenitally missing lateral incisors requires a complex therapeutic approach aimed at rehabilitating the smile, both in terms of function and aesthetics $[39,40]$.

Literature describes different treatment options: space closure with mesial repositioning of the canine, followed by tooth recontouring or space opening followed by placement of a prosthesis, transplant or dental implant [41]. Implant placement is considered one of the best solutions in order to obtain an ideal occlusion together with resinbonded fixed dental prostheses [42, 43]. The orthodontic closure of space, on the other hand, is considered an ideal therapeutic option for adolescent patients as it does not require to wait until the end of the growth period to perform implant surgery as well as for resin-bonded fixed dental prostheses $[18,44]$.

The closure or opening of spaces in agenesis cases depends on the space discrepancy in the arch, type of facial profile, presence of maxillary dental protrusion or retrusion, type of malocclusion, the presence of dental crowding, agenesis symmetry and size and shape of teeth to be moved. The aesthetic factor is important in the planning of orthodontic treatment for the closure or the opening of the spaces. A bi-protruded or convex profile with protrusion of the upper incisors, a balanced profile with normo-inclined anterior teeth and a minimum or absent space in the arch are indications for the closure of the agenesis space. From the occlusion point of view, class II in neutral occlusion without basal dental discrepancy, class II with basal dental discrepancy treated with inferior extractions, class I with lower crowding, an increased $\mathrm{OVJ}$ and an open bite require the closure of the space. The aesthetic analysis of the canine is also necessary: if the canine is mesialized, small, flat with an acceptable color, compatible with the adjacent teeth, the closure of the space is indicated. On the contrary, in the presence of a concave or flat profile, of class III or class I with tendency to class III, of lower diastemas, diminished OVJ, deep bite, global big, well localized and dark-colored canines, it is recommended to open spaces and to plan rehabilitation with implants [45-50].

To obtain correct implant rehabilitation from both aesthetic (a good dental emergence profile) and functional points of view, an adequate bone thickness and an adequate space is necessary. Appropriate space is determined by occlusion, by aesthetics (golden proportion: ideally the lateral incisor should have a width of about two-thirds of the central incisor) and by the distances between the implant and the adjacent teeth that should ideally correspond to about $1.4 \mathrm{~mm} \mathrm{[49].} \mathrm{Standard-diameter} \mathrm{implants}$ 
require a sufficient width of the alveolar ridge $(>5.5 \mathrm{~mm})$ and the critical condition for good osseointegration is to have an amount of at least $2 \mathrm{~mm}$ of healthy bone around the implant [51, 52]. These conditions are not always available in the presence of agenesis of the lateral incisors. Besides, several studies show that the orthodontic opening for the insertion of an endosseous implant generates a reduction in the height and width of the bone crest. Several methods were offered to solve the problem of scant bone thickness in those cases requiring an implant-prosthetic rehabilitation: techniques to change the axis of insertion of the implants, exposing the prosthetic restoration to the concrete risk of failure, techniques of ridge augmentation (guided bone regeneration) with re-absorbable membrane, bone grafting, ridge expansion using split-crest, ERE (edentulous ridge expansion) and RRO (ridge expansion osteotomy). These bone augmentation procedures increase the risk of possible side effects, costs and treatment duration [53].

The data collected in the present study showed that dental mini-implants could be a valid prosthodontic alternative to standard-diameter implants in patients with narrow alveolar ridges and small interdental space such as in cases with lateral agenesis (40-41).

No statistically significant differences ( $p$-value $>0.05$ ) were found using Wilcoxon test comparing the parameters taken into consideration (pain, vertical and horizontal mobility in the presence of a force of $5 \mathrm{~N}$, amount of alveolar bone resorption, bleeding) during the 10-year follow-up nor conducting a case-complete analysis on the remaining 42 implants installed in patients who were regularly followedup nor considering the worst-case scenario (in which five implants loss to follow-up are assumed to have all failed) (Tables 3 and 4).

Even assuming a worst-case scenario, of the 47 implants used, success rates range from $96 \%(n=45$ at the first month) to the $89 \%$ ( $n=42$ at 5 and 10 years). Presumed failed implants (five loss to follow-up) were $4 \%$ at the first month, $6 \%$ at the first year and $11 \%$ at 5 and 10 years that is well below the $20 \%$ suggested as posing bias by the literature [54].

As the Little test and telephone survey between missing patients suggested that the lost data were Missing Completely At Random, authors are encouraged to consider unbiased the results of the full case analysis [55-57] in a follow-up to 10 years which are equal to $100 \%(n=42)$.

Anyway, Wilcoxon-Mann-Whitney test showed a $p$-value $>0.05$ thus indicating that there were no statistically significant differences, comparing the results for the parameters taken into consideration from the complete-case analysis with the ones of the worst case scenario (Table 5).

The overall results considered over 10 years range from $89 \%$ of success rate in a worst-case scenario to the $100 \%$ using a complete-case analysis and are compatible with those found in the literature for shorter periods of time [58, 59].

In this study survival rate of mini-implants in a 10-year follow-up is equal to $100 \%$ : no patients experienced pain ( $p$-value $>0.05$ ), all mini-implants showed no visible vertical and horizontal movements ( $p$-value $>0.05$ ) and no alveolar bone resorption ( $p$-value $>0.05$ ). Bleeding was presented in 7 cases after 1 month, in 6 cases after 1 year, in 5 cases after 5 years and 5 cases after 10 years ( $p$-value $>0.05$ ).

On the 42 mini-implants kept continuously under observation over 10 years, no patients of the thirty ones who have been followed experienced pain ( $p$-value $>0.05$ ), all miniimplants showed no visible vertical and horizontal movements ( $p$-value $>0.05)$ and no alveolar bone resorption ( $p$-value $>0.05)$. Bleeding was presented in 7 implants after 1 month, in 6 cases after 1 year, in 5 cases after 5 years and 5 cases after 10 years ( $p$-value $>0.05$ ) (Table 3 ).

It was not associated with alveolar bone resorption and it had a remission after oral hygiene. Implants showed very good stability over time, absence of inflammation and of clinical or radiographic signs of progressive peri-implantitis. All the abutments were surrounded by healthy and stable peri-implant soft tissues, thanks to the correct design of the final restorations and to the maintenance of good oral hygiene. Aesthetical results on the time are satisfactory with no signs of infraocclusion. In fact, clinical and radiological evaluations did not show vertical changes of mini-implants to the adjacent anterior maxillary teeth in 10-year followup in discordance with literature. Several authors reported the presence of infraocclusion for standard size implants probably due to the continuous eruption of adjacent natural teeth and to the growth of the jaws during adolescence and post-adolescence [35, 60-62].

This study, the first to evaluate the behavior of the miniimplants in 10 years, showed no signs of infraocclusion probably thanks to (i) one-piece structure of mini-implants, (ii) to the small diameters of mini-implants that would allow following the movement of the surrounding bone structures and (iii) to the type of osseointegration (mini-implants can be unscrewed with a small torque wrench). Probably, miniimplants contribute to the maintenance of bone properties, bone density, height and width of the alveolar process and they could benefit from the blood supply and uncomplicated healing provided by growing bone [63-65].

Long-term survival studies are lacking and acceptable short-term survival rates $(>90 \%)$ of mini-implants are only documented for mandibular overdentures. In a multi-center study, the 4-year survival rate of mini-implants for complete denture stabilization was about $95 \%$ without significant differences between the maxilla and mandible [58]. The mean bone loss was insignificantly higher in the maxilla $(0.8 \mathrm{~mm})$ than in the mandible $(0.5 \mathrm{~mm})$ [66]. In another study on 
mini-implant supported mandibular overdentures, delayed loading appeared to be preferable to immediate loading regarding implant survival and bone loss [67]. Different studies show that the mean radiographic bone loss rates between 0.4 and $1.2 \mathrm{~mm}$ [68].

Medium-term follow-up is documented only in a few case-reports and no studies evaluated marginal bone resorption and the peri-implant tissue conditions with a long-term follow-up [53, 68, 69].

Zarone et al. evaluated the marginal bone resorption and the peri-implant tissue conditions around Narrow-Neck ITI implants in 30 patients by $24-39$-month prospective clinical study and present satisfactory values of marginal bone resorption and optimal conditions of peri-implant tissue over time [70]. Rafałowicz et al. assessed the effects of maxillary lateral incisor hypodontia treatment following the use of implantation procedures, fixed and removable dental prostheses, and change in the shape of the canine after a 9 year of follow-up. The results showed that mini-implants with porcelain fused to metal crowns and three-unit porcelainfused-to-metal fixed partial dentures are the most effective treatment methods [71]. In a review, Gleiznys et al. showed survival rates between 91.17 and $100 \%$ in a follow-up duration that ranged from 4 months to 8 years [59].

Mini-implants could be considered a valid therapeutic alternative to resin-bonded fixed dental prostheses and to standard size implants considering follow-up and costeffectiveness. Data of literature are discordant. While some authors believed that resin-bonded fixed dental prostheses are the optimal solutions in the long term [18, 19], other authors considered resin-bonded fixed dental prosthesis a conservative alternative option wherever possible considering occlusion, state of dentition and tooth conservation as several factors influence its long-term survival (detachment of the restoration, fracture of the porcelain) [72].

Besides, the long-term cost-effectiveness analysis (especially for single-tooth replacement) showed that the cantilevered resin-bonded fixed dental prostheses are not the most cost-effective, long-term option for treatment also considering that the cost of one mini-implants is 3.5 times lower than that of standard size implants [73-75].

\section{Conclusion}

The literature regarding the treatment of maxillary lateral incisor agenesis shows different options: space closure with mesial repositioning of the canine, space opening followed by placement of transplant, prosthesis, resin-bonded fixed dental prostheses or dental implant. This retrospective study, the first to evaluate the behavior of the mini-implants in 10 years, showed a survival rate equal to $100 \%$ with satisfactory values of marginal bone resorption and good conditions of the peri-implant tissue.

This retrospective study, the first to evaluate the behavior of the mini-implants in 10 years, showed a survival rate which ranges from $89 \%$ in a worst-case scenario to the $100 \%$ using a complete-case analysis with satisfactory values of marginal bone resorption and good conditions of the peri-implant tissue.

Mini-implants could be considered a reliable and predictable treatment from an aesthetic, functional and cost-effectiveness point of view. They could be indicated for areas in which the use of implants needs additional bone augmentation/expansion procedures. However, it is necessary to pay particular attention in assessing the bone quality of the implant sites and to maintain good oral hygiene over time to ensure a high success rate.

Acknowledgements The authors express their gratitude to Paparella Vincenzo for the pictures' improvement and to Mastrorillo Alessandro Gaetano for his support to the authors in drafting the paper.

Author contribution Lacarbonara M. and Cazzolla A.P. are cofirst authors and contributed equally to the paper.

All authors substantially contributed to the study conception and design

All authors critically revised the manuscript for important intellectual content.

All authors read and approved the final manuscript. All authors agree to be accountable for all aspects of the work in ensuring that questions related to the accuracy or integrity of any part of the work are appropriately investigated and resolved.

Funding Open access funding provided by Università di Foggia within the CRUI-CARE Agreement.

\section{Declarations}

Ethics approval The study has been approved by the ethics committee of Foggia and L'Aquila (Italy) (protocol number 153-CE-2020/30-11-2020).

Conflict of interest The authors declare no competing interests.

Open Access This article is licensed under a Creative Commons Attribution 4.0 International License, which permits use, sharing, adaptation, distribution and reproduction in any medium or format, as long as you give appropriate credit to the original author(s) and the source, provide a link to the Creative Commons licence, and indicate if changes were made. The images or other third party material in this article are included in the article's Creative Commons licence, unless indicated otherwise in a credit line to the material. If material is not included in the article's Creative Commons licence and your intended use is not permitted by statutory regulation or exceeds the permitted use, you will need to obtain permission directly from the copyright holder. To view a copy of this licence, visit http://creativecommons.org/licenses/by/4.0/.

\section{References}

1. Altug-Atac AT, Erdem D (2007) Prevalence and distribution of dental anomalies in orthodontic patients. Am J Orthod Dentofacial 
Orthop 131(4):510-514. https://doi.org/10.1016/j.ajodo.2005.06. 027

2. Pinho T, Tavares P, Maciel P, Pollmann C (2005) Developmental absence of maxillary lateral incisors in the Portuguese population. Eur J Orthod 27(5):443-449. https://doi.org/10.1093/ejo/cji060

3. Bozga A, Stanciu RP, Manuc D (2014) A study of prevalence and distribution of tooth agenesis. J Med Life 7(4):551-554

4. Alvesalo L, Portin P (1969) The inheritance pattern of missing, peg-shaped, and strongly mesio-distally reduced upper lateral incisors. Acta Odontol Scand 27(6):563-575

5. Robertsson S, Mohlin B (2000) The congenitally missing upper lateral incisor. A retrospective study of orthodontic space closure versus restorative treatment. Eur J Orthod 22(6):697-710. https:// doi.org/10.1093/ejo/22.6.697

6. Peck S, Peck L, Kataja M (1996) Prevalence of tooth agenesis and peg-shaped maxillary lateral incisor associated with palatally displaced canine (PDC) anomaly. Am J Orthod Dentofacial Orthop 110(4):441-443

7. Baccetti T (1998) A controlled study of associated dental anomalies. Angle Orthod 68(3):267-274. https://doi.org/10.1043/00033219(1998)068\%3c0267:ACSOAD\%3e2.3.CO;2

8. Cazzolla AP, Zhurakivska K, Ciavarella D, Lacaita MG, Favia G, Testa NF, Marzo G, La Carbonara V, Troiano G, Lo Muzio L (2018) Primary hyperoxaluria: orthodontic management in a pediatric patient: a case report. Spec Care Dentist 38(4):259-265. https://doi.org/10.1111/scd.12302

9. Cazzolla AP, Lo Muzio L, Di Fede O, Lacarbonara V, Colaprico A, Testa NF, Giuseppe T, Zhurakivska K, Marzo G, Lacaita MG (2018) Orthopedic-orthodontic treatment of the patient with Turner's syndrome: review of the literature and case report. Spec Care Dentist 38(4):239-248. https://doi.org/10.1111/scd.12295

10. Cazzolla AP, Testa NF, Favia G, Lacaita MG, Ciavarella D, Zhurakivska K, Troiano G, Lo Muzio L (2018) Multidisciplinary approach in a case of Hand-Schuller-Christian disease with maxillary involvement. Spec Care Dentist 38(2):107-111. https://doi. org/10.1111/scd.12273

11. Cazzolla AP, Troiano G, Zhurakivska K, Maiorano E, Favia G, Lacaita MG, Marzo G, Dicuonzo F, Andresciani S, Muzio LL (2017) Langerhans cell histiocytosis of the maxillae in a child treated only with chemotherapy: a case report. J Med Case Reports 11(1):130. https://doi.org/10.1186/s13256-017-1286-3

12. Favia G, Lacaita MG, Limongelli L, Tempesta A, Laforgia N, Cazzolla AP, Maiorano E (2014) Hyperphosphatemic familial tumoral calcinosis odontostomatologic management and pathological features. Am J Case Rep 15:569-575. https://doi.org/10. 12659/AJCR.892113

13. Lacarbonara M, Cazzolla AP, Lacarbonara VA, Di Venere D, Capogreco M, Marzo G (2014) Prolidase deficiency: dentofacial aspects in a paediatric patient. Eur J Paediatr Dent 15(2 Suppl):224-228

14. Cazzolla AP, Lacaita MG, Lacarbonara V, Zhurakivska K, De Franco A, Gissi I, Testa NF, Marzo G, Lo Muzio L (2019) Orthopedic and orthodontic management in a patient with DiGeorge syndrome and familial Mediterranean fever: a case report. Spec Care Dentist 39(3):340-347. https://doi.org/10.1111/scd.12381

15. Lo Muzio L, Tetè S, Mastrangelo F, Cazzolla AP, Lacaita MG, Margaglione M, Campisi G (2007) A novel mutation of gene CBFA1/RUNX2 in cleidocranial dysplasia. Ann Clin Lab Sci 37(2):115-120

16. Millar BJ, Taylor NG (1995) Lateral thinking: the management of missing upper lateral incisors. Br Dent J 179(3):99-106

17. Hebel K, Gajjar R, Hofstede T (2000) Single-tooth replacement: bridge vs. implant-supported restoration. J Can Dent Assoc 66(8):435-438
18. Botelho MG, Chan AW, Leung NC, Lam WY (2016) Long-term evaluation of cantilevered versus fixed-fixed resin-bonded fixed partial dentures for missing maxillary incisors. J Dent 45:59-66

19. Kern M, Passia N, Sasse M, Yazigi C (2017) Ten-year outcome of zirconia ceramic cantilever resin-bonded fixed dental prostheses and the influence of the reasons for missing incisors. J Dent 65:51-55

20. DeDominicis WE (2002) Implant replacement of congenitally missing lateral incisor: a case report. J Oral Implantol 28(6):279282. https://doi.org/10.1563/1548-1336(2002)028\%3c0279: IROCML\%3e2.3.CO;2

21. Zuccati G (2004) Orthodontics and implant therapy to replace a congenitally missing lateral incisor. J Clin Orthod 38(10):563-567

22. Pini NI, Marchi LM, Pascotto RC (2014) Congenitally missing maxillary lateral incisors: update on the functional and esthetic parameters of patients treated with implants or space closure and teeth recontouring. Open Dent J 8:289-294. https://doi.org/10. 2174/1874210601408010289

23. Misch C E.(2008). Density of bone: effects on surgical approach and healing. Contemporary Implant Dentistry, CE Misch (ed):645-667

24. Quinzi V, Scibetta ET, Marchetti E, Mummolo S, Gianni AB, Romano M, Beltramini G, Marzo G (2018) Analyze my face. J Biol Regul Homeost Agents 32(2 Suppl. 1):149-158

25. Favia G, Tempesta A, Limongelli L, Crincoli V, Maiorano E (2016) Medication-related osteonecrosis of the jaws: considerations on a new antiresorptive therapy (denosumab) and treatment outcome after a 13-year experience. Int J Dent 2016:1801676. https://doi.org/10.1155/2016/1801676

26. Favia G, Tempesta A, Limongelli L, Crincoli V, Maiorano E (2016) Medication-related osteonecrosis of the jaw after once-ayear intravenous zoledronic acid infusion for osteoporosis: report of eight cases. Quintessence Int 47(5):433-440. https://doi.org/ 10.3290/j.qi.a35263

27. Favia G, Tempesta A, Limongelli L, Crincoli V, Maiorano E (2018) Medication-related osteonecrosis of the jaw: surgical or non-surgical treatment? Oral Dis 24(1-2):238-242. https://doi. org/10.1111/odi.12764

28. Lacarbonara M, Lacarbonara V, Cazzolla AP, Spinelli V, Crincoli V, Lacaita MG, Capogreco M (2017) Odontomas in developmental age confocal laser scanning microscopy analysis of a case. Eur J Paediatr Dent 18(1):77-79. https://doi.org/10.23804/ejpd.2017. 18.01.16

29. Crincoli V, Tettamanti L, Lucchina AG, Dedola A, Cazzolla AP, Lacaita MG, Mastrangelo F (2019) Correlation between maxillary canine impaction and facial biotype. J Craniofac Surg 30(4):10441048. https://doi.org/10.1097/scs.0000000000005279

30. Karimbux N, Weber H-P (2017) Clinical cases in implant dentistry. John Wiley \& Sons

31. Cecchinato D, Parpaiola A, Lindhe J (2013) A cross-sectional study on the prevalence of marginal bone loss among implant patients. Clin Oral Implants Res 24(1):87-90

32. Behneke A, Behneke N, Hoedt DB (2002) A 5-year longitudinal study of the clinical effectiveness of ITI solid-screw implants in the treatment of mandibular edentulism. Int J Oral Maxillofac Implants 17(6):799-810

33. McClanahan SF, Bartizek RD, Biesbrock AR (2001) Identification and consequences of distinct Löe-Silness Gingival Index examiner styles for the clinical assessment of gingivitis. J Periodontol 72(3):383-392

34. James P, Worthington HV, Parnell C, Harding M, Lamont T, Cheung A, Whelton H, Riley P (2017) Chlorhexidine mouthrinse as an adjunctive treatment for gingival health. Cochrane Database Syst Rev (3)

35. Bernard J, Schatz J, Christou P, Belser U, Kiliaridis S (2004) Long-term vertical changes of the anterior maxillary teeth 
adjacent to single implants in young and mature adults: a retrospective study. J Clin Periodontol 31(11):1024-1028

36. Little RJ (1988) A test of missing completely at random for multivariate data with missing values. J Am Stat Assoc 83(404):1198-1202

37. Rubin DB (1976) Inference and missing data. Biometrika 63(3):581-592

38. Mukaka M, White SA, Terlouw DJ, Mwapasa V, Kalilani-Phiri L, Faragher EB (2016) Is using multiple imputation better than complete case analysis for estimating a prevalence (risk) difference in randomized controlled trials when binary outcome observations are missing? Trials 17:341-341. https://doi.org/10.1186/ s13063-016-1473-3

39. Rosa M, Zachrisson BU (2007) Integrating space closure and esthetic dentistry in patients with missing maxillary lateral incisors. J Clin Orthod 41(9):563-573 (quiz 424)

40. Turpin DL (2004) Treatment of missing lateral incisors. Am J Orthod Dentofacial Orthop 125(2):129. https://doi.org/10.1016/ S088954060301076X

41. Sabri R (1999) Management of missing maxillary lateral incisors. J Am Dent Assoc 130(1):80-84

42. Lam WY, Botelho MG, McGrath CP (2013) Longevity of implant crowns and 2-unit cantilevered resin-bonded bridges. Clin Oral Implants Res 24(12):1369-1374

43. Lam WY, McGrath CP, Botelho MG (2014) Impact of complications of single tooth restorations on oral health-related quality of life. Clin Oral Implants Res 25(1):67-73

44. Jamilian A, Perillo L, Rosa M (2015) Missing upper incisors: a retrospective study of orthodontic space closure versus implant. Prog Orthod 16:2. https://doi.org/10.1186/s40510-015-0072-2

45. Behr M, Proff P, Leitzmann M, Pretzel M, Handel G, Schmalz G, Driemel O, Reichert TE, Koller M (2011) Survey of congenitally missing teeth in orthodontic patients in Eastern Bavaria. Eur J Orthod 33(1):32-36. https://doi.org/10.1093/ejo/cjq021

46. Kinzer GA, Kokich VO Jr (2005) Managing congenitally missing lateral incisors. Part III single-tooth implants. J Esthet Restor Dent 17(4):202-210

47. Torres FC, de Freitas CF, Pereira DV, Trivino T, Fuziy A, Maeda FA (2018) Agenesis of all permanent maxillary incisors: a rare clinical case with an interdisciplinary solution. J Clin Exp Dent 10(4):e402-e407. https://doi.org/10.4317/jced.54698

48. Silveira GS, de Almeida NV, Pereira DM, Mattos CT, Mucha JN (2016) Prosthetic replacement vs space closure for maxillary lateral incisor agenesis: a systematic review. Am J Orthod Dentofacial Orthop 150(2):228-237. https://doi.org/10.1016/j.ajodo.2016. 01.018

49. Kokich VG (2004) Maxillary lateral incisor implants: planning with the aid of orthodontics. J oral and maxillofacial surg : official J Am Assoc Oral Maxillofacial Surg 62(9 Suppl 2):48-56

50. Kokich VO Jr, Kinzer GA (2005) Managing congenitally missing lateral incisors. Part I: Canine substitution. J Esthet Restor Dent 17(1):5-10

51. Branemark PI, Adell R, Breine U, Hansson BO, Lindstrom J, Ohlsson A (1969) Intra-osseous anchorage of dental prostheses. I. Experimental studies. Scand J Plast Reconstr Surg 3(2):81-100

52. Branemark PI, Hansson BO, Adell R, Breine U, Lindstrom J, Hallen O, Ohman A (1977) Osseointegrated implants in the treatment of the edentulous jaw. Experience from a 10-year period. Scand J Plast Reconstr Surg Suppl 16:1-132

53. Bidra AS, Almas K (2013) Mini implants for definitive prosthodontic treatment: a systematic review. J Prosthet Dent 109(3):156164. https://doi.org/10.1016/S0022-3913(13)60035-9

54. Nahler G (2009) loss to follow-up. In: Dictionary of pharmaceutical medicine. Springer Vienna, Vienna, pp 107-107. https://doi. org/10.1007/978-3-211-89836-9 804
55. Little RJ, D'Agostino R, Cohen ML, Dickersin K, Emerson SS, Farrar JT, Frangakis C, Hogan JW, Molenberghs G, Murphy SA (2012) The prevention and treatment of missing data in clinical trials. N Engl J Med 367(14):1355-1360

56. Bartlett JW, Harel O, Carpenter JR (2015) Asymptotically unbiased estimation of exposure odds ratios in complete records logistic regression. Am J Epidemiol 182(8):730-736. https://doi.org/ 10.1093/aje/kwv114

57. Little RJ, Rubin DB (2019) Statistical analysis with missing data, vol 793. John Wiley \& Sons

58. Mundt T, Schwahn C, Stark T, Biffar R (2015) Clinical response of edentulous people treated with mini dental implants in nine dental practices. Gerodontology 32(3):179-187. https://doi.org/ 10.1111/ger.12066

59. Gleiznys A, Skirbutis G, Harb A, Barzdziukaite I, Grinyte I (2012) New approach towards mini dental implants and small-diameter implants: an option for long-term prostheses. Stomatologija 14(2):39-45

60. Thilander B, Ödman J, Jemt T (1999) Single implants in the upper incisor region and their relationship to the adjacent teeth An 8 year follow up study. Clin Oral Implants Res 10(5):346-355

61. Daftary F, Mahallati R, Bahat O, Sullivan RM (2013) Lifelong craniofacial growth and the implications for osseointegrated implants. Int J Oral \& Maxillofac Implants 28 (1)

62. Papageorgiou SN, Eliades T, Hämmerle CH (2018) Frequency of infraposition and missing contact points in implant-supported restorations within natural dentitions over time: a systematic review with meta-analysis. Clin Oral Implants Res 29:309-325

63. Bohner L, Hanisch M, Kleinheinz J, Jung S (2019) Dental implants in growing patients: a systematic review. Br J Oral Maxillofac Surg 57(5):397-406

64. Giannetti L, Murri Dello Diago A, Vecci F, Consolo U (2010) Mini-implants in growing patients: A case report. Pediatr Dent 32(3):239-244

65. Giannetti L, Apponi R, Murri Dello Diago A, Mintrone F (2020) Rehabilitation of a patient with mini-implants after avulsion of the upper incisors: a 13-year follow up. Dent Traumatol

66. Mundt T, Schwahn C, Biffar R, Heinemann F (2015) Changes in bone levels around mini-implants in edentulous arches. Int J Oral Maxillofac Implants 30(5):1149-1155. https://doi.org/10.11607/ jomi.4012

67. Maryod WH, Ali SM, Shawky AF (2014) Immediate versus early loading of mini implants supporting mandibular overdentures: a preliminary 3-year clinical outcome report. Int J Prosthodont 27(6):553-560

68. Scepanovic M, Calvo-Guirado JL, Markovic A, Delgardo-Ruiz R, Todorovic A, Milicic B, Misic T (2012) A 1-year prospective cohort study on mandibular overdentures retained by mini dental implants. Eur J Oral Implantol 5(4):367-379

69. Klein MO, Schiegnitz E, Al-Nawas B (2014) Systematic review on success of narrow-diameter dental implants. Int J Oral Maxillofac Implants 29(Suppl):43-54. https://doi.org/10.11607/jomi.2014s uppl.g1.3

70. Zarone F, Sorrentino R, Vaccaro F, Russo S (2006) Prosthetic treatment of maxillary lateral incisor agenesis with osseointegrated implants: a 24-39-month prospective clinical study. Clin Oral Implants Res 17(1):94-101. https://doi.org/10.1111/j.16000501.2005.01188.x

71. Rafalowicz B, Wagner L (2019) Assessment of hypodontia treatment of maxillary lateral incisors in adult patients after 9 years of follow-up a retrospective study. Int J Prosthodont 32(1):9-13. https://doi.org/10.11607/ijp.5822

72. Balasubramaniam G (2017) Predictability of resin bonded bridges-a systematic review. Br Dent J 222(11):849

73. Antonarakis GS, Prevezanos P, Gavric J, Christou P (2014) Agenesis of maxillary lateral incisor and tooth replacement: 
cost-effectiveness of different treatment alternatives. Int J Prosthodont 27 (3)

74. Vogel R, Smith-Palmer J, Valentine W (2013) Evaluating the health economic implications and cost-effectiveness of dental implants: a literature review. Int J Oral Maxillofac Implants 28 (2)

75. Griffitts TM, Collins CP, Collins PC (2005) Mini dental implants: an adjunct for retention, stability, and comfort for the edentulous patient. Oral Surg, Oral Med, Oral Pathol, Oral Radiol, Endodontol 100(5):e81-e84
Publisher's note Springer Nature remains neutral with regard to jurisdictional claims in published maps and institutional affiliations. 